\title{
A Subjective Related Measure of Airborne Sound Insulation
}

\author{
Reinhard O. Neubauer and Jian Kang \\ School of Architecture, University of Sheffield, Western Bank, Sheffield S10 2TN, UK
}

(Received 1 May 2015; accepted 19 April 2016)

\begin{abstract}
In many practical cases, the objective measures of airborne sound insulation using standard procedures do not agree with subjective assessments. This paper describes a calculation scheme based on the loudness level linked to the specific fluctuation strength and yields a weighted normalized loudness level difference. Evidence has been presented through a subjective evaluation that the model can be considered to be a link between an objective and subjective evaluation. The stimuli offered in the experiment were electronically filtered sound samples representing the sound insulation of interest. Steady-state and non-steady state signals are used as stimuli. To differentiate the signal in terms of psychoacoustic measures, investigations of music type signals were focused on specific fluctuation strength. An assessment of identical airborne sound insulation experimental results has shown that steady-state signals were assessed to be significantly quieter than non-steady-state signals, which also yield greater specific fluctuation strength. As expected, sound insulation was judged differently for different sound samples. A simple level difference is shown not to exhibit the effects of a given signal to the frequency-dependent airborne sound insulation curve. This study supports findings in the literature that airborne sound insulation performance is significantly dependent on what type of sound signal is used.
\end{abstract}

\section{INTRODUCTION}

The quality of sound insulation in buildings is generally described using a single number rating of the sound insulation and has an important bearing on the comfort, health, and general amenity of the residents. ${ }^{1-3}$ In many cases, however, single-number ratings do not correlate well with subjective expectations. ${ }^{4}$ Comparing single number quantities of airborne sound insulation with subjectively estimated airborne sound insulation frequently yields significant differences. ${ }^{4,5}$ In the literature, complaints have even been made regarding partitions fulfilling specific requirements with respect to airborne sound insulation. ${ }^{6-9}$ Therefore, it is necessary to establish a better understanding of airborne sound insulation through the use of psychoacoustics. Neubauer and Kang introduced a concept describing a frequency-dependent weighted normalized loudness level difference. ${ }^{10-12}$ This concept is intended to be a connection between the objective measure of airborne sound insulation and the psychoacoustic measures of the loudness level and fluctuation strength.

This study investigates the previously introduced calculation scheme describing the airborne sound insulation in terms of a probability of the insulation's "best fit." This means that if a certain airborne sound insulation is compared with its "unbiased" airborne sound insulation, as e.g. calculated, the airborne sound insulation of the real construction is biased by means of resonances, leakages or other effects, which can influence the airborne sound insulation.

This paper first describes the inapplicability of standards to rate airborne sound insulation in terms of a subjective assessment, and second discusses the new model of a weighted normalized loudness level difference. Finally, it validates the model by comparing subjective test results and clarifies the dis- crepancies among sound insulation and the weighted normalized loudness level difference.

\section{EXPERIMENT ON THE SUBJECTIVE EVALUATION ON SOUND SIGNALS}

To determine the subjective assessment of different test signals for different sound insulation values, hearing tests were conducted. The main goal for this investigation is to find evidence that the perceived sound is judged differently if the signal is changed and if the spectrum of the airborne sound insulation is different. It is, therefore, vital to know how the model depicts differences in sound signals and spectra and how the differences are related to subjective assessments.

\subsection{Excitation Signals}

From the literature, ${ }^{13-15}$ it is known that music is reported as one of the most frequently detected noises even in dwellings that fulfil sound insulation requirements. Therefore, the influence of using different signals is investigated by using two categories of signals: steady-state and non-steady-state signals. The steady-state signals are broadband noise signals: "pink noise" (PN) and "white noise" (WN). These signals are selected because they are recommended in standards for measuring airborne sound insulation. The non-steadystate signals, i.e., the transient signals, were music samples, namely rap (Eminem: "Lose Yourself") (E) and classic music (Beethoven's Symphony No. 9: Poco Allegro, Stringendo Il Tempo, Sempre Piu Allegro-Prestissimo) (B). This type of music was also investigated earlier. ${ }^{16-18}$ 


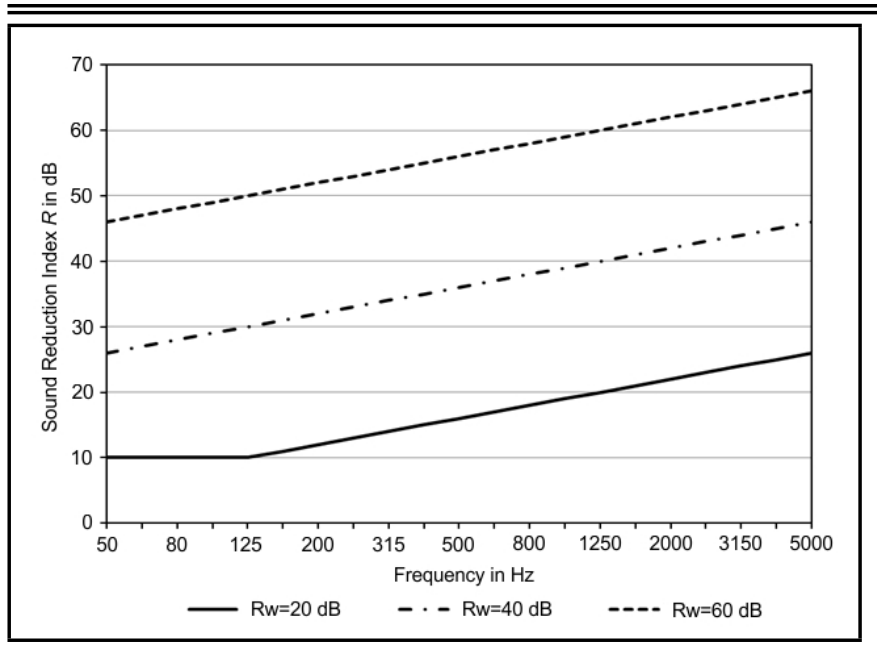

Figure 1. Hypothetical sound insulation over frequency used as the respective filter.

\subsection{Perception of Damped Sound Signals}

A pilot test was conducted in order to find an indication whether a sound signal will be differently judged if the damping and the sound signals used as a source signal is different.

Nine untrained participants, five females and four males were asked to listen to some sound samples via headphone (Sennheiser HD 280 pro) and judge the sound by answering pre-coded questions. The headphone was closed-back ensuring a $32 \mathrm{~dB}$ attenuation of external noise. The ear coupling was circumaural and its frequency response is $8 \mathrm{~Hz}-25,000 \mathrm{~Hz}$. The acoustic stimuli were played in different sequences for the participants to decrease the order effects. The background noise level was less than $25 \mathrm{~dB}(\mathrm{~A})$. The participants had normal hearing abilities and the median of age was 34 . The stimuli used were the electronically filtered sound samples of the sound signal described in section 2.1 using a filter function representing the sound insulation of interest.

The insulation curves did not differ in their shape. In Fig. 1, the applied filter functions are depicted. The participants were asked to select one of the following answers: 0 - I do not hear a sound; 1 - I can hear a weak sound; 2 - I hardly hear a sound; 3 - Yes, I can hear a sound but not easily; 4 - Yes, I can hear a sound when I concentrate on it; 5 - Yes, I can hear a sound; and 6 - Yes I can clearly hear a sound.

The source signals, white and pink noise and Eminem and Beethoven as described above, were used. Due to the small sample $(n=9)$, the non-parametric Wilcoxon test, i.e., the Wilcoxon signed-rank test, was applied instead of the most commonly applied t-test. In contrast to the t-test, the Wilcoxon test does not require the data set to be normally distributed. A summary of the results is shown in Fig. 2 where the boxplot of response distribution for the data samples is shown. The sound samples were observed to be generally judged similar. However, as shown in Fig. 2, where the calculated mean for different $R_{w}$-values is shown, the music signal type was generally judged to be heard clearer than the broadband noise signal type.

From Fig. 2, it is seen that white noise has lowest median whereas pink noise and the music type signals have the same. From comparison it is seen that in summery Eminem

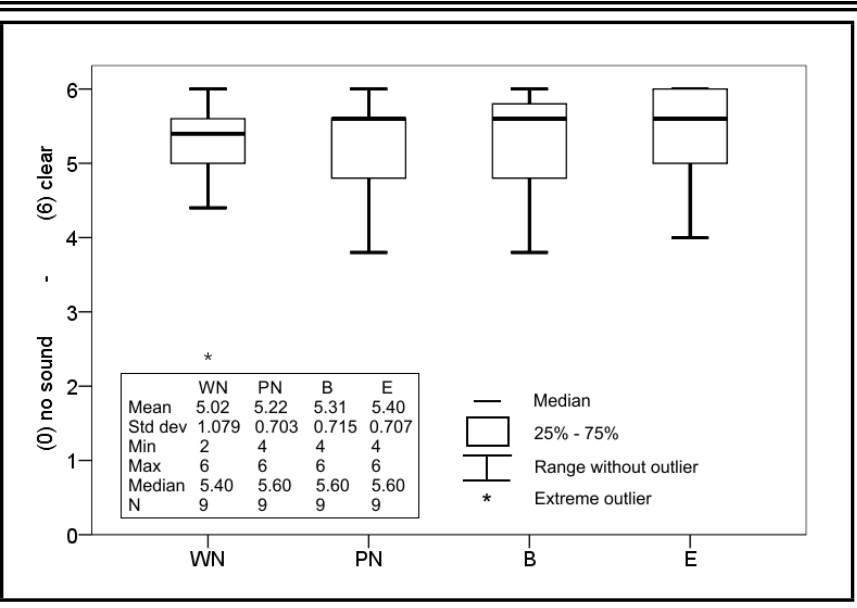

Figure 2. Results and boxplot of the response distribution for the data samples of white noise, pink noise, Beethoven, and Eminem.

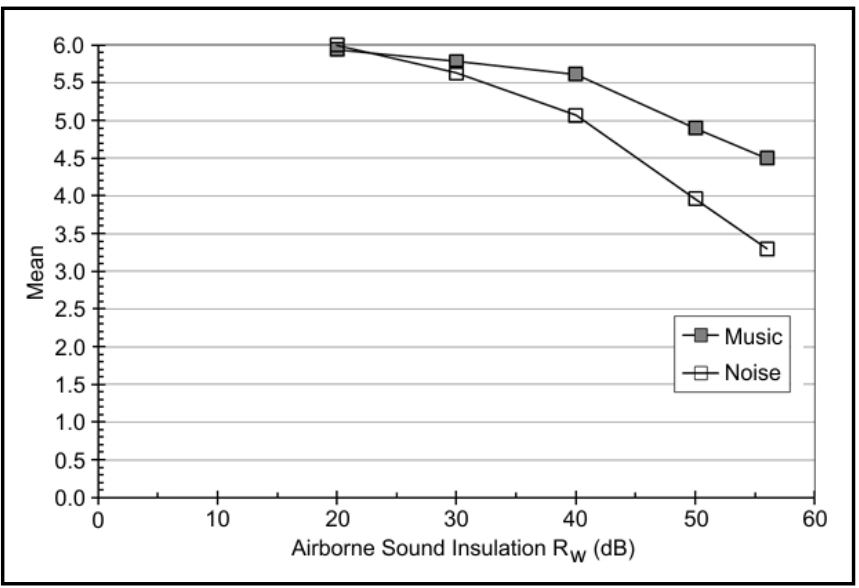

Figure 3. Mean of the grouped and overall grouped response distribution.

was judged "louder" (from data in Fig. 2: $5.4 \pm 0.7$ ) than Beethoven (from data in Fig. 2: $5.3 \pm 0.7$ ). Overall, the music group (B, E) was judged as: can hear / can clearly hear, while the noise group (WN, PN) was judged as: can hear when concentrate on it / can hear. Both groups differ in judgment of the subject by one category, which means noise sound samples are judged not as loud as music sound samples. From Fig. 2, the pink noise was observed to be judged louder than the white noise, and "Eminem" was judged to be heard slightly clearer than "Beethoven".

As shown in Fig. 3, the overall grouped response distribution of the two different sound samples was assessed differently.

The results of this experiment demonstrate that different sound samples are judged differently with respect to loudness. To summarize the results, music was found to be judged as being heard clearer than a noise type sound signal. This finding was observed for the increasing $R_{w}$-values. At a low airborne sound insulation of approximately 20 and $30 \mathrm{~dB}$, little difference was observed. For this experiment, it was concluded that broadband noise was not as "audible" as music if the damping increases beyond $40 \mathrm{~dB}$. A comparison of the music type sound sources revealed that Eminem was judged more audible at high sound insulations compared with the Beethoven. Although the data sample is small in this experiment, certain conclusions can still be drawn. This is in line with results pub- 


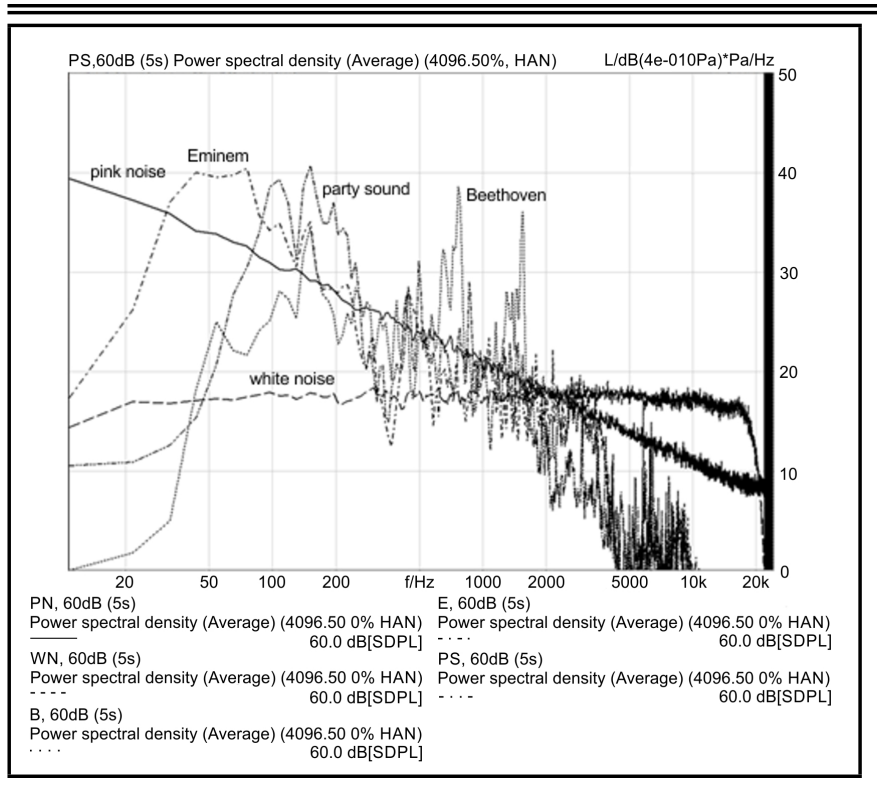

Figure 4. Power spectral density (PSD) as a function of frequency in the range of $20 \mathrm{~Hz}$ to $20 \mathrm{kHz}$. Depict is Beethoven (B), Eminem (E), pink noise (PN), white noise (WN), and party sound (PS), all having sound pressure level of 60 $\mathrm{dB}$, and duration $5 \mathrm{~s}$.

lished by Zwicker and Feldkeller, ${ }^{19}$ Takeshima et al. ${ }^{20}$ and Soeta et al., ${ }^{21}$ where subjective experiments were conducted with small numbers of participants. It is thought that music is heard stronger compared with broadband noise; this result is consistent with everyday experiences.

\subsection{Perception of Different Sound Signals}

Following the pilot study performed in the first test, the aim of this second listening test was to find evidence that the type of sound signal heard is judged different in loudness depending on the type of signal. For this test, 100 untrained participants, 8 females, and 92 males were asked to listen to sound samples via loudspeakers and to judge the loudness. The participants had normal hearing abilities and the median of age was 46. This different presentation method of the acoustical stimuli was needed because the test was conducted for all participants simultaneously. The acoustic stimuli were played back in different sequences for the participants to reduce the order effects.

The experiment involved 5 different sounds: WN, PN, E, B, and PS with three different sound levels (i.e. 40, 50, and $60 \mathrm{~dB}$ SPL) and was designed such that every sound was compared against all others. In Fig. 4 an example of the power spectral density over frequency is shown for sound signals having sound pressure level of $60 \mathrm{~dB}$.

The participants were presented with two sound signals one after the other with both signals having the same sound pressure level. The duration of one sound sample was $5 \mathrm{~s}$. Each sound pair was played in a row, and the participant was asked to decide whether the latter sound was louder or quieter than the former and was asked to rate the sound from -5 to +5 , where -5 indicates "much quieter," and +5 "much louder." Zero indicates on the other hand "equally loud". In the experiment, all 5 sounds were joined in 12 pair comparisons (such as WN: WN vs. PN, WN vs. E, WN vs. B and WN vs. PS; at $40 \mathrm{~dB}, 50 \mathrm{~dB}$ to $60 \mathrm{~dB})$. The evaluation in a pair comparison is in line with

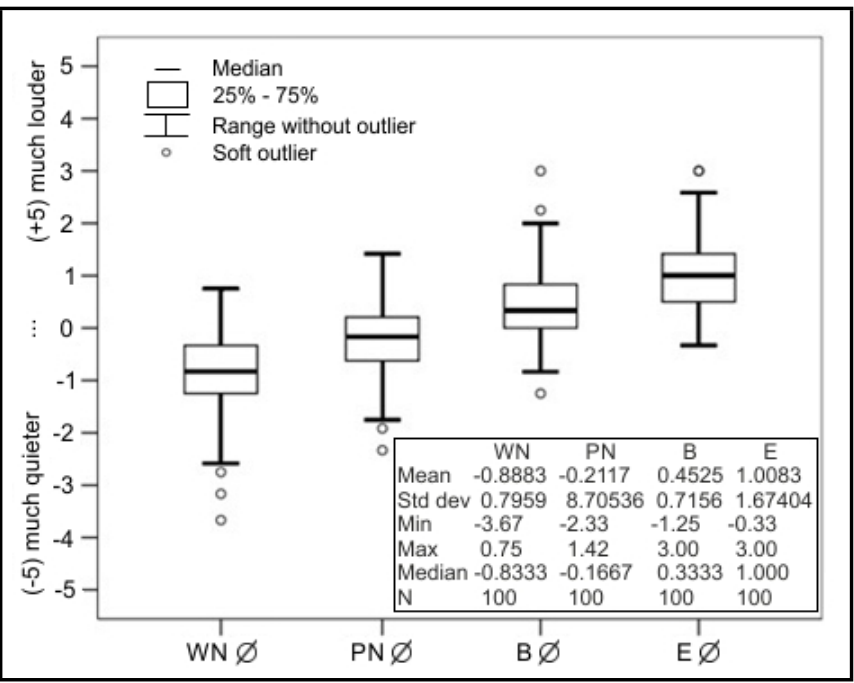

Figure 5. Results of the second experiment displayed as a boxplot of the response distribution data comparing all the results.

\section{the literature (Soeta et al.; Jeon et al.). ${ }^{21,22}$}

The obtained data was compared using the t-test for related samples and the Wilcoxon test to determine whether the mean differences between the sounds (if the sounds were quieter or louder) were significant. The analyses demonstrated that with regard to the significant $(p<0.05)$ differences between the sounds, the white noise (WN) was judged highly significantly $(p<0.001)$ "quieter" compared with the other sound samples. A summary of the results is shown in Fig. 5 where the boxplot of the response distribution for the data samples is shown.

The data from Fig. 5 indicates that, as the value decreases, the particular sound will be perceived as quieter by all participants. White noise was judged overall to be quietest. Eminem was the loudest. This confirmed the results of the first pilot survey shown in Fig. 2. It is noted that a differentiation between gender has not been investigated which is in line with literature. ${ }^{21-24}$

\subsection{Detecting Different Airborne Sound Insulations}

The goal of the third listening test was to find evidence that the perceived sound level after transmission differs with different frequencies depending on the airborne sound insulation that has the same single $R_{w}$-value. The equipment used and the procedure of this test was the same as that for the first test, although the number of participants was 11 , there were $3 \mathrm{fe}$ males and 8 males. The participants had normal hearing and the median age was 42 . Two types of airborne sound insulation, i.e., the filter types had to be judged and were labelled " $I$ and II." The single values of the filters are I: $R_{w}\left(C ; C_{t r}\right)=$ $50(-1 ;-1) d B$ and II: $R_{w}\left(C ; C_{t r}\right)=50(-3 ;-7)$, respectively (the frequency depending airborne sound insulation is depicted in the lower panel of Fig. 13). These filter functions were calculated according to ISO 717-1. ${ }^{25}$

All source signals had sound pressure levels of $85 \mathrm{~dB}$ and had a duration of 15 seconds. The participants were asked to listen to the sound and to rank the sounds from the quietest to the loudest. The subjects could listen to the sound samples 


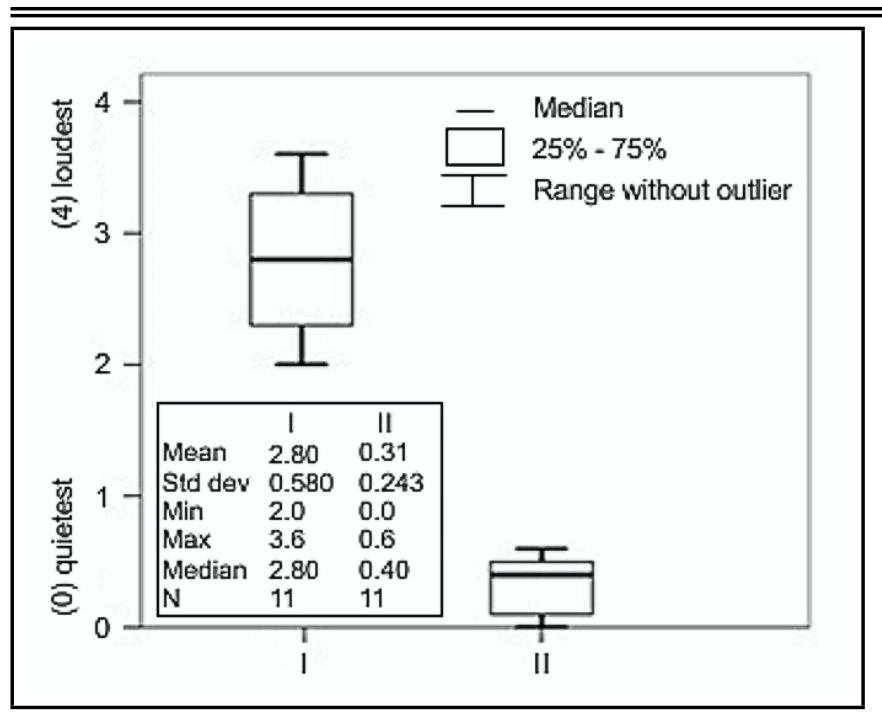

Figure 6. Results of the third experiment displayed as a boxplot of the response distribution for the data samples, Case $I: R_{w}=50(-1 ;-1) \mathrm{dB}$ and Case II: $R_{w}=50(-3 ;-7) \mathrm{dB}$.

as often as they wanted. The participants were asked to select one of the following answers: 0 - quietest; 1 - quiet; 2 - equal; 3 - loud; and 4 - loudest. All sounds per filter were combined and averaged for the data evaluation. This was done because the analysis concerns the comparison of the two filters and not the comparison of the sound signal. From the data collected from the listening tests, an evaluation was performed. The data collected was summarized and described quantitatively in Fig. 6. Considering the sample size $(n=11)$, the non-parametric Wilcoxon test was applied as opposed to the t-test. It is seen in Fig. 6 that case "II" was judged to be quieter than case "I." Case "II" is statistically significantly $(p<0.05)$ different from filter "I." This result is a strong indication that the airborne sound insulation is judged differently (i.e., subjectively) depending on the frequency dependent $R_{w}$-value. Comparing the spectra of the respective sound insulation and the resulting $C$-values indicates that case "II" has little sound insulation at low frequencies and a dip at $800 \mathrm{~Hz}$, whereas case 'I" has high sound insulation at low frequencies and a dip at $2.5 \mathrm{kHz}$. This could be an indication that low frequencies do not contribute significantly to the subjective assessment of a sound insulation. This finding is in line with that of Hongisto ${ }^{26}$ and is worthy of further investigations in the field of subjective assessment tests.

\section{MODEL BASED ON WEIGHTED NORMAL- IZED LOUDNESS LEVEL DIFFERENCE}

From the section above, it is observed that a transmitted sound is judged differently given different types of signals and different sound insulation values. The result of the third listening test has shown that the participants judged the sounds differently, although the damping was the same. There seems to be a discrepancy between the standard calculation procedure to derive an airborne sound insulation value, such as the weighted sound reduction index $R_{w}$, and subjective observation. It is, however, noted that the spectrum adaptation terms indicated a dependency on a subjective assessment, which is not yet related to a subjective assessment. Therefore, the new model is discussed to demonstrate the discrepancy between the standard measure of a weighted sound reduction index $\left(R_{w}\right)$ and a subjective observation of affected persons, such as an inhabitant in a dwelling for example. The new model proposed by Neubauer and Kang ${ }^{11}$ aims to integrate both discrepancies. This section first discusses the new measure of a weighted normalized loudness level difference.

\subsection{The Normalized Level Difference}

When measuring a transmission loss, it is common to measure a sound pressure level difference. The frequency depending sound pressure level $(L)$ is then transformed into a frequency depending loudness level by following the procedure outlined in ISO $226 .^{23}$

$$
L(f) \rightarrow L_{N}(f) .
$$

The level difference characterised by the weighted sound reduction index $\left(R_{w}\right)$ without a $\operatorname{dip}\left(L_{0}\right)$ and with a $\operatorname{dip}\left(L_{m}\right)$ provides a set of loudness level differences. The level difference of the idealized (i.e. hypothetical or computed) airborne sound insulation for third-octave bands is given by Eq. (2):

$$
\Delta L_{0(f)}=L_{N 1(f)}-L_{N 2(f), 0} .
$$

The level $L_{N 1}$ is the loudness level in the source room and $L_{N 2}$ is the loudness level in the receiving room. The idealised airborne sound insulation to obtain $\left(L_{N 2,0}\right)$ may be found using a prediction model, as provided by e.g., EN $12354,{ }^{27}$ or by assuming a reference curve e.g., ISO 717. The level difference of an actual (i.e., measured or simulated) airborne sound insulation for third-octave bands is given by Eq. (3):

$$
\Delta L_{m(f)}=L_{N 1(f)}-L_{N 2(f), m}
$$

where $L_{N 2, m}$ is the loudness level in the receiving room obtained by the measured or simulated sound pressure level.

The normalized level difference with respect to the idealized level difference for the third-octave band values is then the following:

$$
L_{n o r}(f)=\frac{\Delta L_{m(f)}}{\Delta L_{0(f)}} .
$$

A method for determining a single value of a sound in terms of a loudness level is given in ISO $532 \mathrm{~B}^{28}$ and in DIN 45631. ${ }^{29}$ The loudness level can be obtained for any sound. ${ }^{30}$ The single number quantity for the normalized loudness level difference $\left(L_{n o r}\right)$ is written as the quotient of the differences of the total loudness levels $\left(L_{N}\right)$, which yields the following:

$$
L_{n o r}=\frac{L_{N 1}-L_{N 2, m}}{L_{N 1}-L_{N 2,0}} .
$$

where $L_{N 1}$ is the single number value of the loudness level in the source room, $L_{N 2,0}$ is the single number value of the loudness level of the idealised or calculated airborne sound insulation in the receiving room, and $L_{N 2, m}$ is the single number value of the loudness level obtained by the measured or simulated sound pressure level. 


\subsection{The Weighting}

The weighting function in the model, as presented in the literature, ${ }^{11}$ is based on some considerations that psychological effects, like annoyance, cannot be fully evaluated by the measurement of the sound pressure level. ${ }^{31}$ The weighting is judged as an awareness of noise, i.e., annoyance. For this reason, some psychoacoustic factors, such as roughness, fluctuation strength, tonality, and sharpness were investigated. ${ }^{17}$ The results led to the conclusion that roughness, tonality, and sharpness are not suitable predictors for a rating procedure concerning sound insulation. From reasons discussed above and because the specific fluctuation strength, $F l s^{\prime}$ (vacil), relates to the temporal structure of the sounds, ${ }^{30,32}$ this measure is preferred to be an appropriate weighting. To differentiate the signal in terms of psychoacoustic measures, investigations were focused on specific fluctuation strength. This is in accordance with investigations concerning indoor acoustic comfort by Jeon et al. ${ }^{33}$ The weighting $(w)$ is the proportion of the frequency depending specific fluctuation strength of the signal being transmitted through an idealized (i.e., hypothetical or calculated) partition, $F l s_{(f), 0}^{\prime}$, and the specific fluctuation strength of the signal being transmitted through an actual (i.e., measured or simulated) partition, $F l s_{(f), m}^{\prime}$. The weighting $(w)$ is given by Eq. (6):

$$
w(f)=\frac{F l s_{m}^{\prime}(f)}{F l s_{0}^{\prime}(f)} .
$$

The total specific fluctuation strength is calculated as the sum of all partial fluctuation strength yielding $F l s^{\prime}$. The single number quantity of the weighting $(w)$ is then the following:

$$
w=\frac{F l s_{m}^{\prime}}{F l s_{0}^{\prime}} .
$$

\subsection{The Weighted Normalized Loudness Level Difference}

The loudness model describes the frequency-dependent airborne sound insulation yielding the weighted normalized loudness level difference. For third-octave band values expressed as the product of the frequency-dependent normalized loudness level difference and a frequency-dependent psychoacoustic weighting factor, the corresponding formula is given in Eq. (8):

$$
L_{n o r, w}(f)=L_{n o r(f)} * w(f) .
$$

Combining Eq. (5) and Eq. (7) yields the single number quantity for the weighted normalized loudness level difference $\left(L_{n o r, w}\right)$ and is written as:

$$
L_{n o r, w}=L_{n o r} * w .
$$

Equation (9) is case sensitive, i.e., $L_{n o r, w}$ depends on the individual results of the level differences and the weighting, as is seen from Eq. (5) and Eq. (6). The following regions occur depending on the six conditions:

$$
\begin{aligned}
I) & L_{n o r}>1 \wedge w>1 \Rightarrow L_{n o r, w}>1 \\
I I) & L_{n o r}<1 \wedge w<1 \Rightarrow L_{n o r, w}<1 \\
I I I)+I V) & L_{n o r}>1 \wedge w<1 \Rightarrow L_{n o r, w}<1 \vee L_{n o r, w}>1 \\
V)+V I) & L_{n o r}<1 \wedge w>1 \Rightarrow L_{n o r, w}<1 \vee L_{n o r, w}>1
\end{aligned}
$$

NB: The region yielding $L_{n o r, w}=1$ needs: $L_{n o r}=1 \wedge$ $w=1$ and that requires: $L_{2, m}=L_{2,0} \wedge F l s_{m}^{\prime}=F l s_{0}^{\prime}$. This condition is impossible in real buildings and in real situations in-situ.

\section{MODEL IMPLEMENTATION}

The filtered sound signal, i.e., the level of interest, is assumed to be a measure of perception, which means that a dip in the frequency dependent airborne sound insulation should be included in the model. This will be demonstrated explicitly for single frequency dips in the frequency dependent airborne sound insulation. The frequency dependent value enables judgment of the frequency range of that dip. The overall performance of the model is then demonstrated by means of a single value representing the measure of deviation from the ideal value. The single value enables, therefore, the judgment of an $R_{w}^{\prime}$-value to be "real" or "untrue." This means if the judged airborne sound insulation is "real," it is likely that the "heard" sound is subjectively equally assessed as calculated. If the airborne sound insulation is "untrue," it is likely that the airborne sound insulation is considered subjectively different from a certain expected airborne sound insulation.

\subsection{Frequency Dependence}

A calculated airborne sound insulation of $40 \mathrm{~dB}$ having a 6 $\mathrm{dB}$ frequency single dip at each $1 / 3^{\text {rd }}$ octave band frequency from $160 \mathrm{~Hz}$ up to $5 \mathrm{kHz}$ is used as an example. In Fig. 7, the investigated idealised airborne sound insulation is shown exemplarily.

Using pink noise as source signal and having a sound pressure level of $85 \mathrm{~dB}$, the calculated frequency dependent normalized loudness level differences $\left(L_{n o r(f)}\right)$ according to Eq. (4) is shown in Fig. 8. A $6 \mathrm{~dB}$ dip is evident. It is noted that the influence of the single frequency dip on the normalized loudness level difference is observed to be at least one-third octave band below and above the dip. This means that the dip enlarges the influence of a single frequency dip to the normalized loudness level difference.

The envelope depicted in Fig. 8 (represented by the dotted line) reveals that with increasing frequency, the minimum value of the normalized loudness level difference decreases. That means that the frequency dip reduces the airborne sound insulation. The maximum value $\left(L_{n o r}>1\right)$ increases for low frequencies was very steep; up to about $160 \mathrm{~Hz}$. From $160 \mathrm{~Hz}$ up to $5 \mathrm{kHz}$, a nearly constant value is virtually observed. The calculated mean and standard deviation for the linear range $(160 \mathrm{~Hz}-5 \mathrm{kHz})$ is $L_{n o r}=1.024 \pm 0.003$. From the envelope it is observed that, for minimum values, the low frequencies are about constant up to $250 \mathrm{~Hz}$. Above that frequency, the 


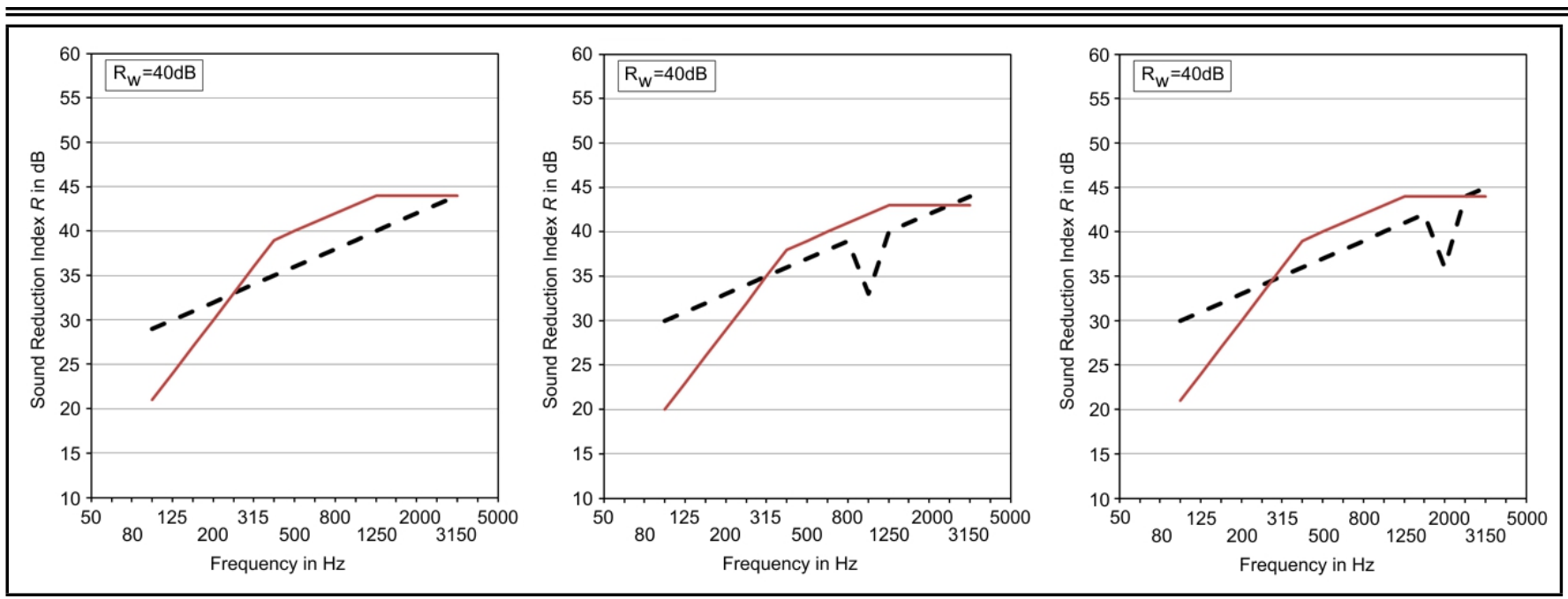

Figure 7. Idealized airborne sound insulation exemplarily for $R_{w}=40 \mathrm{~dB}$ without (left panel) and with a dip of $6 \mathrm{~dB}$ at the exemplarily depicted frequency of $1 \mathrm{kHz}$ (middle panel) and $2 \mathrm{kHz}$ (right panel). The solid line is the reference curve given in ISO 717-1.

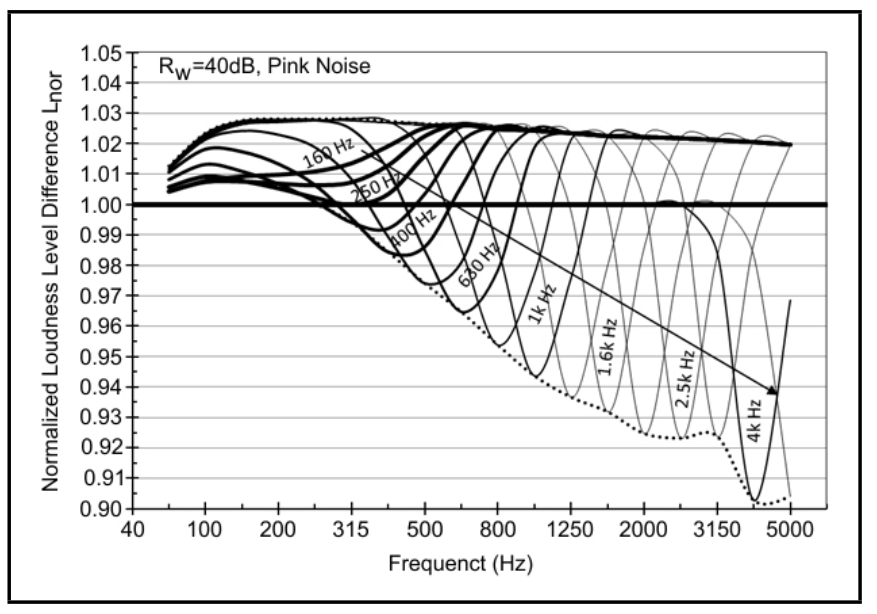

Figure 8. Normalized loudness level difference over various frequencies, $R_{w}=40 \mathrm{~dB}$ with a single dip of $6 \mathrm{~dB}$ at each $1 / 3^{r d}$ octave band frequency from $160 \mathrm{~Hz}$ up to $5 \mathrm{kHz}$. The source signal is pink noise having a SPL of $85 \mathrm{~dB}$. Each solid line shows $L_{n o r}$ with a dip at one frequency and the dotted line shows the envelope.

values decreased linearly until a frequency of approximately $2.5 \mathrm{kHz}$. Above that frequency, some deviation was observed. Overall, the investigated influence of the dip yield in the case of the normalized loudness level difference for all the investigated sound signals demonstrated that the filtered or processed sound was assumed to be louder when a frequency dip is introduced in the airborne sound insulation. Although the single value of the airborne sound insulation is not altered much, the dip is thought to cause a sensation that result in an increased loudness. Introducing the weighting $(w)$, as defined in Eq. (6), results in the weighted normalized loudness level difference $\left(L_{n o r, w(f)}\right)$, as defined in Eq. (4). See the results illustrated in Fig. 9 for an example; pink noise was used as a source signal.

The weighted normalized loudness level difference shows the event of a frequency dip in a manner similar to the normalized loudness level difference. It is observed, however, that a reversed picture is drawn comparing the normalized loudness level difference and the weighted normalized level difference. This is an indication that the specific fluctuation strength does significantly influence the weighted normalized loudness level difference.

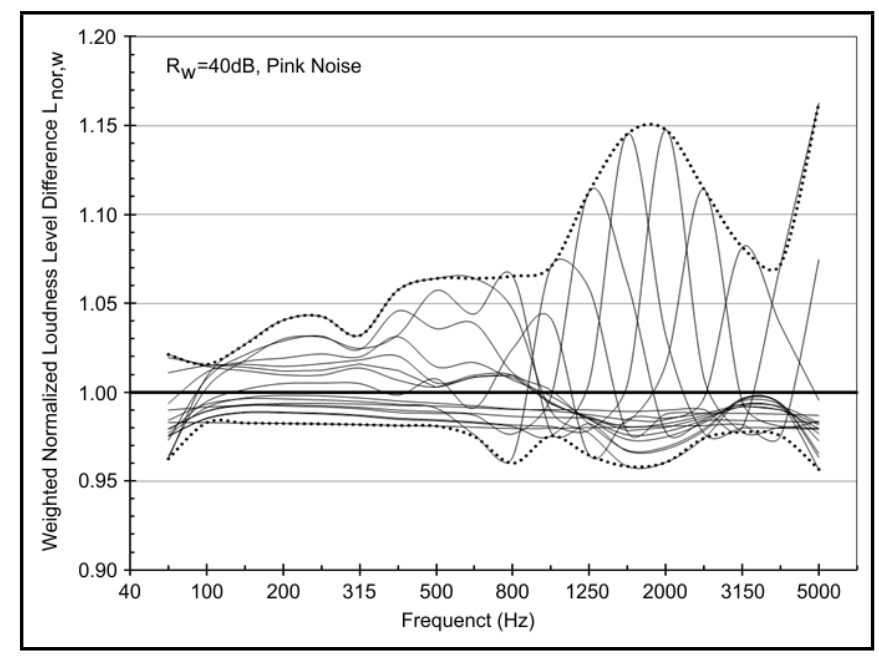

Figure 9. Weighted normalized loudness level difference over various frequencies, $R_{w}=40 \mathrm{~dB}$ with a single dip of $6 \mathrm{~dB}$ at each $1 / 3^{r d}$ octave band frequency from $160 \mathrm{~Hz}$ up to $5 \mathrm{kHz}$. The source signal is pink noise having a SPL of $85 \mathrm{~dB}$. Each solid line shows $L_{n o r, w}$ with a dip at one frequency and the dotted line indicates the envelope.

\subsection{Specific Fluctuation Strength}

The calculated specific fluctuation strength $\left(F l s^{\prime}\right)$ for different sound signals and different $R_{w}$-values reveal that transient sound signals, i.e., the music type signals (Eminem and Beethoven), have greater values than the broadband noise signals (pink noise and white noise). The results are shown in Fig. 10.

From Fig. 10 it is seen that with increasing $R_{w}$-value the fluctuation strength decreases. Broadband noise shows little or almost no fluctuation, whereas music type signals show high fluctuation. This is expected, is in line with the literature, ${ }^{34}$ and confirms the results presented earlier. ${ }^{35}$ Broadband noise signals (pink noise or white noise) do not change much in specific fluctuation strength with increasing sound insulation, which is expected, but this result could be an indication that transient signals, i.e., non-steady-state signals, can be more influenced by appropriate sound insulation in the sense of subjective judgments to rate the annoyance of the receiving sound between a dividing partition. ${ }^{17,33}$ 


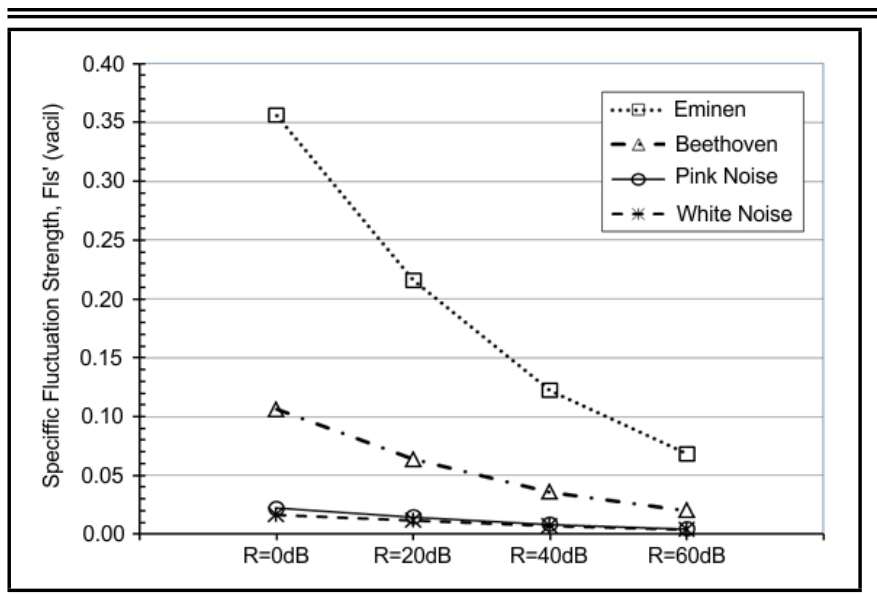

Figure 10. Specific fluctuation strength (Fls') for different sound signals and different $R_{w}$-values.

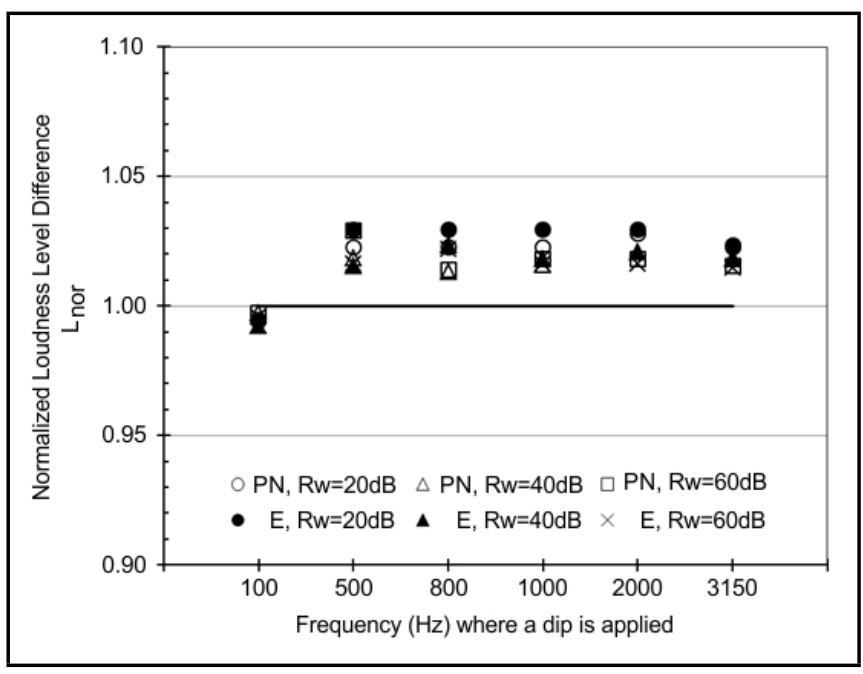

Figure 11. Normalized loudness level difference (Lnor) for different Rwvalues over frequency where a dip of $6 \mathrm{~dB}$ is applied in the frequency curve of the sound insulation.

\subsection{Normalized Loudness Level Differences}

The result from computing the single number quantities of the normalized loudness level differences $\left(L_{n o r}\right)$ as defined in Eq. (5) for different $R_{w}$-values of 20,40 , and $60 \mathrm{~dB}$ with frequency dips of $6 \mathrm{~dB}$ at 100,500,800,1k, 2k, and $3.15 \mathrm{kHz}$ in the airborne sound insulation are shown in Fig. 11.

In Fig. 11, each symbol shows the calculated result of $L_{\text {nor }}$ for different $R_{w}$-values that have a frequency dip of $6 \mathrm{~dB}$ at $100,500,800,1 \mathrm{k}, 2 \mathrm{k}$, and $3.15 \mathrm{kHz}$ in the airborne sound insulation. From this comparison, it is observed that the level difference does not show much deviation with respect to different types of sound signals. At low frequencies $(100 \mathrm{~Hz})$, the difference between the investigated signals is smallest. Inspecting results at a single value reveal that at a frequency of $100 \mathrm{~Hz}$ the normalized loudness level difference is less than or equal to unity. This result means that the dip, i.e., the "biased" airborne sound insulation, is less than or equal to the "ideal", i.e., predicted airborne sound insulation. For greater frequencies, the normalized loudness level difference is greater than unity. Hence, the "biased" airborne sound insulation is supposed to be greater than the predicted value. This result might indicate that a dip at low frequencies yields a subjectively re-

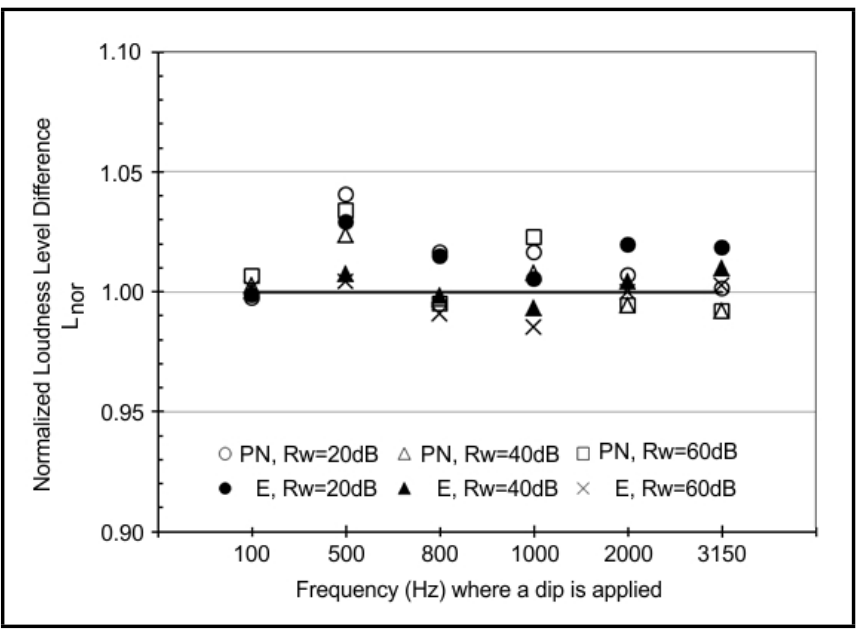

Figure 12. Weighted normalized loudness level difference $\left(L_{n o r, w}\right)$ for different $R_{w}$-values over frequency where a dip of $6 \mathrm{~dB}$ is applied in the frequency curve of the sound insulation.

lated finding that a predicted airborne sound insulation is overestimated compared to a "biased" sound insulation.

\subsection{Weighted Normalized Loudness Level Differences}

From the explored single number quantities of the normalized loudness level differences, the same airborne sound insulations of 20,40 , and $60 \mathrm{~dB}$ with frequency dips at 100 , $500,800,1 \mathrm{k}, 2 \mathrm{k}$, and $3.15 \mathrm{kHz}$ at $6 \mathrm{~dB}$ are used to compute the weighted normalized loudness level difference $\left(L_{n o r, w}\right)$ according to Eq. (9). The results are shown in Fig. 12.

The influence of the type of signal used to compute the weighted normalized loudness level difference is clearly observed. However, at $100 \mathrm{~Hz}$, no significant difference between the used signal types was observed. A clear variation of the weighted normalized loudness level difference was observed for frequencies greater than $100 \mathrm{~Hz}$. Obviously the weighting had a key influence on the result in calculating the weighted normalized loudness level difference. This is in agreement with the theory used to describe an auditory judgment using a psychoacoustic measure, such as the specific fluctuation strength. ${ }^{31}$ The single numerical value of the weighted normalized loudness level difference is sensitive to the type of test signal and to an introduced frequency dip.

\section{MODEL VERIFICATION}

To verify the validity of the model, the results obtained by the listening tests shown in Figs. 2 to 5 are compared.

\subsection{Calculated Frequency Depending Values}

The normalized loudness level difference and the weighted normalized loudness level difference are calculated for the two cases shown in Fig. 5. The idealised airborne sound insulation to obtain $\left(L_{N 2,0}\right)$ was chosen to be the shifted reference curve having a sound reduction index of $R_{w}=50(-2 ;-6) \mathrm{dB}$. The results are shown in Fig. 13, which provides a direct visual comparison of the results. The sound reduction index $R_{w}$ is 


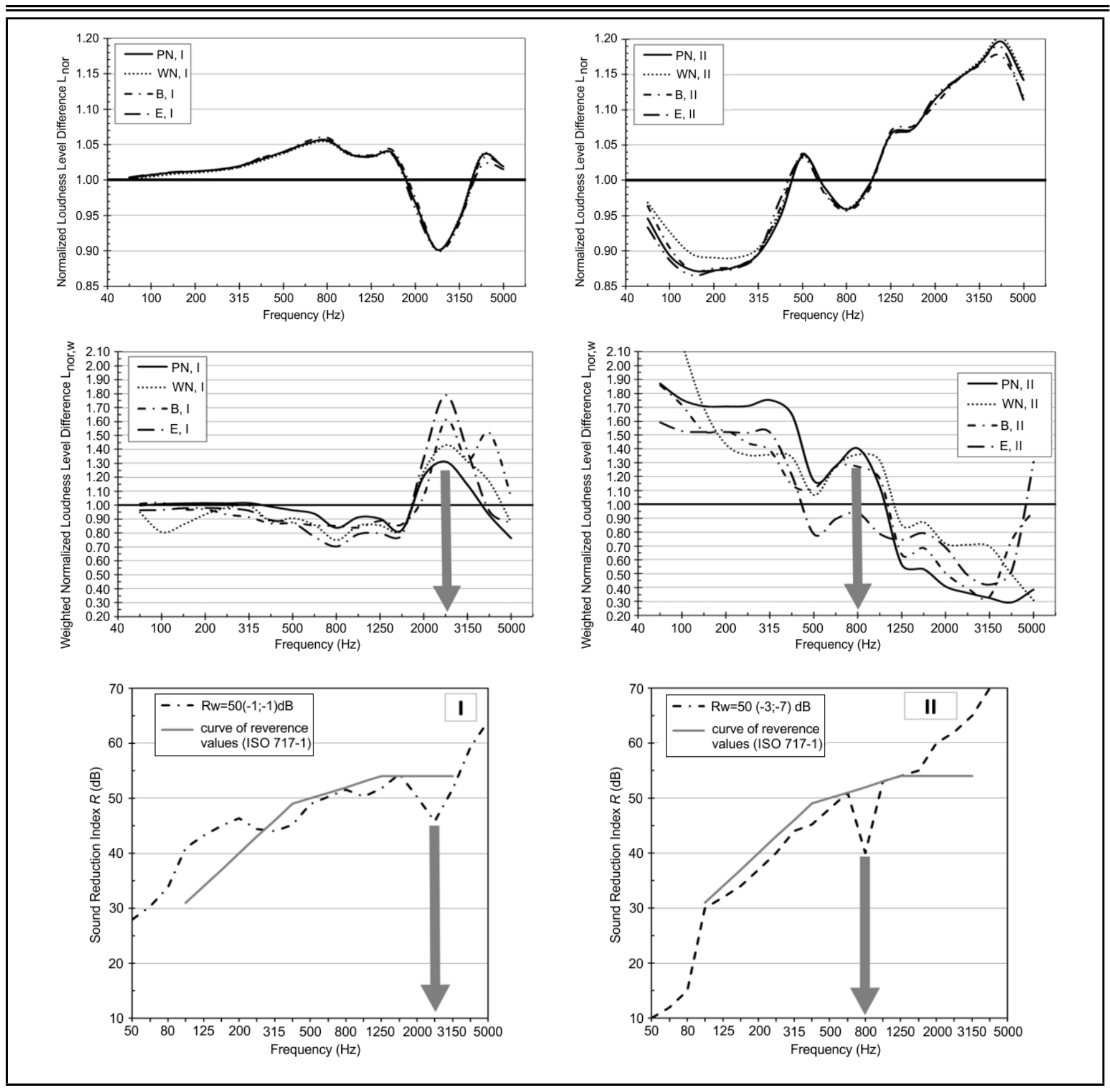

Figure 13. Weighted normalized loudness level difference $\left(L_{n o r, w}\right)$ for different $R_{w}$-values over frequency where a dip of $6 \mathbf{d B}$ is applied in the frequency curve of the sound insulation.

also depicted separately below Fig. 13. It is seen that the frequency dependent normalized loudness level difference does not discriminate between different sound signals, whereas the weighted normalized loudness level difference does. Furthermore, the frequency dip is observed in all calculation results. A comparison of the data shows that the frequency dips in case "I" at $2.5 \mathrm{kHz}$ and in case "II" at $800 \mathrm{~Hz}$, it is accurately pictured. Results from the listening test have shown that case "I" (left panel in Fig. 12) was judged to be louder than case "II." This is also pictured in Fig. 12, where the weighted normalized loudness level difference for case "I" is, which is at frequencies greater than $1.250 \mathrm{~Hz}$ that clearly beyond unity and thus, indicates that the sound insulation is different from the calculated or "expected" value. Moreover, in case "I" (left panel in Fig. 13), the music type signal is greater than the broadband noise signal, which is in line with the results found in the first experiment.

\subsection{Calculated Single Numerical Values}

Computing the weighted normalized loudness level difference for the two cases $I$ and $I I$ as single values yields results that are shown in Fig. 14. The results outlined in Fig. 14 show that the weighted normalized loudness level difference $\left(L_{n o r, w}\right)$ diverges in some way. The results, however, reveal that case "I" results in values close to unity, which means that the expected sound insulation is achieved. The calculated mean and standard deviation are $1.003 \pm 0.025$. Furthermore, it is observed that the white noise results are greater than unity in both cases "I" and "II," which means that the sound insulation is supposed to be greater as calculated. The interpretation 


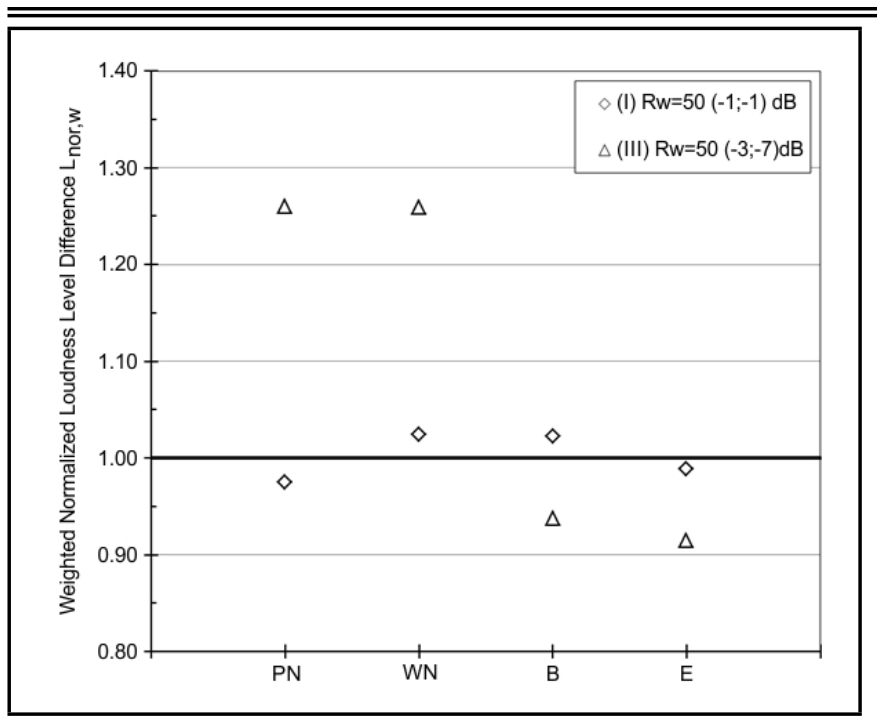

Figure 14. Weighted normalized loudness level difference $\left(L_{n o r, w}\right)$ for cases "I" and "II" and for different sound samples. The airborne sound insulation is $R_{w}=\mathbf{5 0} \mathrm{dB}$ with varying spectral adaptation terms $C$ and $C_{t r}$.

is that the "biased" airborne sound insulation is thought to be, in a subjective sense, greater than the "unbiased" or predicted value. From the subjective test, it was found that white noise is judged to be quieter than the other sound samples (see Fig. 4). Thus, it is concluded that, white noise as a test signal causes a fictive increase in the airborne sound insulation. It is further concluded from the results in Fig. 14 that the sound insulation of case "I" is, for all sound samples, "reliable" because the single numerical value is close to unity whereas case "II" deviates significantly between different sound samples. This result indicates that the sound insulation of case "II" differs with different sound signals, and hence, the expected airborne sound insulation is not supposed to be consistent with different applied sound samples.

\section{CONCLUSIONS}

The experimental results have revealed that white noise was assessed to be highly significant $(p<0.001)$ quieter, and the rap music sample "Eminem" was judged to be louder compared with the other sound samples. Furthermore, the experiments have shown that, in general, noise samples (i.e., white noise and pink noise) are judged to be not as loud as music sound samples, which also result in lower specific fluctuation strength values. Conversely, non-steady-state signals yield the greatest specific fluctuation strength values and were judged to be louder than the broadband noise samples. In other words, sound insulation is judged differently for different sound samples, as expected. The model was shown to correctly depict the experimental results of the loudest and quietest sound samples as well as the individual frequency dips in the airborne sound insulation.

The implementation of the model showed that the calculation scheme is able to capture details in the frequency range as well as in the case of single numerical values. As shown by the comparison of calculated values with experimental results, the weighted normalized loudness level difference demonstrates dependencies on different signal characteristics and different airborne sound insulations.

The model allows sound insulation to be evaluated in a more psychoacoustic manner, rather than only by looking at the sound pressure level differences. This approach could be a prime tool for investigating airborne sound insulation having identical single number ratings but different spectra. The most interesting question is, however, which airborne sound insulation spectrum yields best damping to prevent annoyance or disturbance. This determination is a task for further investigations in the field of subjective assessment tests.

\section{REFERENCES}

1 Langdon, F. J., Buller, I. B., and Scholes, W. E. Noise from Neighbours and the Sound Insulation of Party Walls in Houses, Journal of Sound and Vibration 79 (2), 205-228, (1981). https://dx.doi.org/10.1016/0022-460x(81)90369-2

2 Bradley, J. S. Subjective Rating of the Sound Insulation of Party Walls, Canadian Acoustics, 11 (4), 37-45, (1983).

3 Ryu, J. K., Jeon, J. Y. Influence of noise sensitivity on annoyance of indoor and outdoor noises in residential buildings, Appl. Acoust., 72, 336-340, (2011). https://dx.doi.org/10.1016/j.apacoust.2010.12.005

4 Joiko, K., Bormann, V. Kraak, W., Durchhören von Sprache bei Leichtbauwänden, Z. Lärmbekämpf. 49 (3), 79-85, (2002).

5 Vorländer, M., Thaden, R. Auralisation of Airborne Sound Insulation in Buildings, Acta Acustica united with Acustica, 86 (1), 70-76, (2000). http://www.ingentaconnect.com/

6 Tonin, R. The BCA 2004 - A Plan for the future, Proc. Acoustics 2004, Australia, 141-149, (2004)

7 Muellner, H., Humer, C. Stani, M. M. Lightweight Building Elements with Improved Sound Insulation Considering the Low Frequency Range, Proc. $3^{\text {rd }}$ Congress of the Alps Adria Acoustics Association, 27-28, Graz, Austria, (2007).

8 Rasmussen, B., Lang, J. How much protection do the sound insulation standards give and is this enough?, Proc. 8th European Conference on Noise Control (EuroNoise), Edinburgh, Scotland, UK, 26-28, (2009).

9 Ljunggren, F., Simmons, C. Hagberg, K., Correlation between sound insulation and occupants' perception - Proposal of alternative single number rating of impact sound, Appl. Acoust. 85, 57-68, (2014). https://dx.doi.org/10.1016/j.apacoust.2014.04.003

10 Neubauer, R. O., Kang, J. Airborne sound insulation based on a model of loudness, Proc. 21st International Congress on Sound and Vibration (ICSV), Beijing, China, 13-17, (2014).

11 Neubauer, R. O., Kang, J. Airborne sound insulation in terms of a loudness model, Appl. Acoust., 85, 34-45, (2014). https://dx.doi.org/10.1016/j.apacoust.2014.03.024 
${ }^{12}$ Neubauer, R.O., Kang, J. A Model Based on Loudness Level to Describe Airborne Sound Insulation, Proceedings of the $43^{\text {rd }}$ International Congress on Noise Control Engineering (InterNoise), Melbourne, Australia, (2014).

${ }^{13}$ Grimwood, C. Complaints about Poor Sound Insulation between Dwellings in England and Wales, Appl. Acoust., 52 (3/4), 211-223, (1997). https://dx.doi.org/10.1016/s0003$682 \times(97) 00027-3$

${ }^{14}$ Park, H. K., Bradley, J. S. Evaluating standard airborne sound insulation measures in terms of annoyance, loudness, and audibility ratings, J. Acoust. Soc. Am., 126 (1), 208219, (2009). https://dx.doi.org/10.1121/1.3147499

15 Masovic, D., Mijic, M. Pavlovic, D. S., Adnadevic, M., Noise in dwellings generated in normal home activities Spectral approach, Proc. 6th Forum Acusticum, Aalborg, Denmark, 1383-1388, (2011).

16 Neubauer R. O, Kang J. What Describes the Airborne Sound Insulation in Technical and Subjective Regard? Proc. 6th Forum Acusticum, Aalborg, Denmark, 17831787, (2011).

${ }_{17}$ Neubauer, R. O., Kang, J. Time Structure Of The Signal In Airborne Sound Insulation, Proc. 9th European Conference on Noise Control (EuroNoise), Prague, Czech Republic, (2012).

18 Neubauer, R. O., Kang, J. Airborne Sound Insulation as a Measure for Noise Annoyance, Proc. 21st International Congress on Acoustics (ICA), Montral, Canada, (2013). https://dx.doi.org/10.1121/1.4798969

19 Zwicker, E., Feldtkeller, R. Über die Lautstärke von Gleichförmigen Geräuschen. (On the loudness of stationary noises), (in German), Acustica 5 (6), 303-316, (1955). http://www.ingentaconnect.com

20 Takeshima, H., Suzuki, Y., Fujii, H., Kumagai, M., Ashihara, K., Fujimori, T., and Sone, T. Equal-loudness contours measured by the randomized maximum likelihood sequential procedure, Acust. Acta Acust. 87 (3), 389-399, (2001). http://www.ingentaconnect.com

21 Soeta, Y., Maruo, T., and Ando, Y. Annoyance of bandpassfiltered noises in relation to the factor extracted from autocorrelation function (L), J. Acoust. Soc. Am., 116 (6), 32753278, (2004). https://dx.doi.org/10.1121/1.1782931

22 Jeon, J. Y., Jeong, J. H., Ando, Y., Objective and Subjective Evaluation of Floor Impact Noise, J. Temp. Des. Arch. Environm., 2 (1), 20-28, (2002). http://www.jtdweb.org/

23 ISO 226. Acoustics - Normal equal-loudness-level contours, International Organization for Standardization, Geneva, (2003).

24 Suzuki, Y., Takeshima, H., Equal-loudness-level contours for pure tones, J. Acoust. Soc. Am., 116 (2), 918-933, (2004). https://dx.doi.org/10.1121/1.1763601
25 ISO 717-1. Acoustics - Rating of sound insulation in buildings and of building elements, Part 1: Airborne sound insulation, International Organization for Standardization, Geneva, (2013).

26 Hongisto, V., Mäkiläb, M., Suokas, M. Satisfaction with sound insulation in residential dwellings - The effect of wall construction. Building and Environment, 85, 309-320, (2015). https://dx.doi.org/10.1016/j.buildenv.2014.12.010

27 EN 12354-1. Building acoustics. Estimation of acoustic performance in buildings from the performance of elements (Part 1: Airborne sound insulation between rooms). European Committee for Standardization (CEN), Brussels, Belgium, (2000).

28 ISO 532/R. Acoustics- Method for Calculating Loudness Level. International Organization for Standardization, Geneva. (Standard confirmed in 2012), (1975).

29 DIN 45631/A1. Berechnung des Lautstärkepegels und der Lautheit aus dem Geräusch-spektrum - Verfahren nach E. Zwicker - Änderung 1: Berechnung der Lautheit zeitvarianter Geräusche, (in German), Beuth Verlag, Berlin, (2010).

30 Fastl, H., Zwicker, E. Psychoacoustics: Facts and Models, $3^{\text {rd }}$ ed., Springer, Berlin, (2007). https://dx.doi.org/10.1007/978-3-540-68888-4

31 Kitamura T, Shimokura R, Sato S, Ando Y. Measurement of Temporal and Spatial Factors of a Flushing Toilet Noise in a Downstairs Bedroom Journal of Temporal Design in Architecture and the Environment, 2 (1), 13-19, (2002). http://www.jtdweb.org/

32 Schöne, P. Messungen zur Schwankungsstärke von amplitudenmodulierten Sinustönen, (Fluctuation Strength of Amplitude-Modulated Tones), (in German), Acustica, 41 (4), 252-257, (1979). http://www.ingentaconnect.com

33 Jeon, J. Y., You, J., Jeong C. I., Kim, S. Y., Jho, M. J. Varying the spectral envelope of airconditioning sounds to enhance indoor acoustic comfort, Building and Environ, 46, 739-746, (2011). https://dx.doi.org/10.1016/j.buildenv.2010.10.005

34 Aures, W. Ein Berechnungsverfahren der Rauigkeit, (in German), ACUSTICA, 58 (5), 268-281, (1985). http://www.ingentaconnect.com/

35 Neubauer, R.O., Kang, J. Rating Airborne Sound Insulation in Terms of Time Structure of the Signal, Proc. 42nd International Congress and Exposition on Noise Control Engineering (InterNoise), New York, USA (2012). 